\title{
Article \\ Landscape of Epidermal Growth Factor Receptor Heterodimers in Brain Metastases
}

\author{
Malcolm Lim ${ }^{1}$, Tam H. Nguyen ${ }^{2}$, Colleen Niland ${ }^{1}$, Lynne E. Reid ${ }^{1}$, Parmjit S. Jat ${ }^{3}$, Jodi M. Saunus ${ }^{1, *,+}$ (D) \\ and Sunil R. Lakhani ${ }^{1,4, *,+(\mathbb{C})}$
}

1 Faculty of Medicine, UQ Centre for Clinical Research, The University of Queensland, Herston, QLD 4029, Australia; m.lim@uq.edu.au (M.L.); c.niland@uq.edu.au (C.N.); Lynne@crunkhorn.com (L.E.R.)

2 Flow Cytometry and Imaging Facility, QIMR Berghofer Medical Research Institute, Brisbane, QLD 4006, Australia; tamhong.nguyen@qimrberghofer.edu.au

3 Department of Neurodegenerative Disease and MRC Prion Unit, UCL Institute of Neurology, Queen Square, London WC1N 3BG, UK; p.jat@prion.ucl.ac.uk

4 Pathology Queensland, Royal Brisbane Women's Hospital, Herston, QLD 4029, Australia

* Correspondence: j.saunus@uq.edu.au (J.M.S.); s.lakhani@uq.edu.au (S.R.L.)

+ These authors contributed equally to this work.

check for updates

Citation: Lim, M.; Nguyen, T.H.; Niland, C.; Reid, L.E.; Jat, P.S.; Saunus, J.M.; Lakhani, S.R. Landscape of Epidermal Growth Factor Receptor Heterodimers in Brain Metastases. Cancers 2022, 14, 533. https://doi.org/10.3390/ cancers14030533

Academic Editors: Renata Duchnowska and Philippe Métellus

Received: 26 December 2021

Accepted: 20 January 2022

Published: 21 January 2022

Publisher's Note: MDPI stays neutral with regard to jurisdictional claims in published maps and institutional affiliations.

Copyright: () 2022 by the authors. Licensee MDPI, Basel, Switzerland. This article is an open access article distributed under the terms and conditions of the Creative Commons Attribution (CC BY) license (https:// creativecommons.org/licenses/by/ $4.0 /)$.

\begin{abstract}
Simple Summary: HER2+ breast cancer patients are treated with agents that tag HER2+ tumour cells for elimination by the immune system, down-modulate HER2 activity and/or block the formation of HER2 dimers, including the neuregulin-1 receptor, HER2-HER3. HER2-targeted therapies prolong survival by lowering the risk of relapse, but do not prevent brain metastases. The reasons for this are not fully understood. We quantified HER2-HER3 dimers in 203 brain metastases, and 34 primary breast tumour samples. Dimer frequency was relatively high in brain metastases from breast, ovarian, lung and kidney cancers, and in brain metastases compared to patient-matched breast tumours; but did not reliably correlate with HER2/HER3 expression or activation. In in vitro experiments, pertuzumab failed to suppress HER2-HER3 dimers in HER2+ breast cancer cells provided with a saturating concentration of neuregulin-1. These findings may provide insights about the differences in intracranial versus extracranial efficacy of HER2-targeted therapies.
\end{abstract}

\begin{abstract}
HER2+ breast cancer patients have an elevated risk of developing brain metastases (BM), despite adjuvant HER2-targeted therapy. The mechanisms underpinning this reduced intracranial efficacy are unclear. We optimised the in situ proximity ligation assay (PLA) for detection of the highaffinity neuregulin-1 receptor, HER2-HER3 (a key target of pertuzumab), in archival tissue samples and developed a pipeline for high throughput extraction of PLA data from fluorescent microscope image files. Applying this to a large BM sample cohort $(n=159)$ showed that BM from breast, ovarian, lung and kidney cancers have higher HER2-HER3 levels than other primary tumour types (melanoma, colorectal and prostate cancers). HER2 status, and tumour cell membrane expression of pHER2 $\left(\mathrm{Y}^{1221 / 1222}\right)$ and pHER3( $\left.\mathrm{Y}^{1222}\right)$ were positively, but not exclusively, associated with HER2HER3 frequency. In an independent cohort $(n=78)$, BM had significantly higher HER2-HER3 levels than matching primary tumours $(p=0.0002)$. For patients who had two craniotomy procedures, HER2-HER3 dimer levels were lower in the consecutive lesion $(n=7 ; p=0.006)$. We also investigated the effects of trastuzumab and pertuzumab on five different heterodimers in vitro: HER2-EGFR, HER2-HER4, HER2-HER3, HER3-HER4, HER3-EGFR. Treatment significantly altered the absolute frequencies of individual complexes in SKBr3 and/or MDA-MB-361 cells, but in the presence of neuregulin-1, the overall distribution was not markedly altered, with HER2-HER3 and HER2-HER4 remaining predominant. Together, these findings suggest that markers of HER2 and HER3 expression are not always indicative of dimerization, and that pertuzumab may be less effective at reducing HER2-HER3 dimerization in the context of excess neuregulin.
\end{abstract}

Keywords: brain metastases; HER family; HER dimers; breast cancer; proximity ligation assay 


\section{Introduction}

Metastatic breast cancer (MBC) remains a significant social and economic burden in many countries around the world. In Australia, it is the second most common cause of cancer-related death in women [1]. Metastasis to the brain is a particularly serious complication because it produces challenging neurological side effects and is difficult to control with existing local and systemic therapies. Around $14 \%$ of all MBC patients experience symptomatic brain recurrence requiring treatment [2]. The cost of care for this group is more than double that of MBC patients without brain involvement, and they have significantly worse clinical outcomes [3,4].

Brain metastasis is common for breast tumours with amplification of the HER2 gene, $E R B B 2[2,5,6]$. Not only do HER2+ patients have an elevated risk of already having brain metastases (BM) when initially diagnosed with breast cancer [7], they are also more likely to die as a direct consequence of this complication [8]. HER2 is one of four human epidermal growth factor receptor (HER) tyrosine kinases (RTKs). Dimerization amongst these receptors is activated by epidermal and neuregulin growth factor ligands (EGF/NRG), promoting pro-oncogenic signalling via the PI3K and MAPK pathways in a variety of malignancies, including BM $[9,10]$. Several mechanisms are thought to contribute to $\mathrm{BM}$ pathogenesis in HER2+MBC, including an intrinsic propensity for growth in the brain, which acts as a sanctuary site for early outgrowth [11]. The natural history of HER2+BM also has an iatrogenic component. Although HER2-targeted therapy can delay intracranial progression, paradoxically, it is also associated with the brain being the first site of recurrence, and a higher incidence of BM overall [12-16]. Lapatinib and trastuzumab are used in the metastatic setting because they prolong survival, but this is primarily by stabilizing extracranial disease [12,17-19].

Unfortunately, none of the existing HER2-targeted agents (lapatinib, neratinib, pertuzumab, trastuzumab, or ado-trastuzumab emtansine) can prevent brain recurrence [20]. The reasons for this appear to be complex, including patchy drug uptake due to unique pharmacokinetics in the brain compartment [21-25], as well as brain-specific acquired resistance. For example, brain-derived neuregulins (NRG) provide a stimulus for the HER3-PI3K cell survival axis [26-28]. This is supported by studies demonstrating increased expression and activation of NRG receptors, HER3 and HER4, in BM compared to matching primary breast and lung tumours [29-32]. NRG1 has a very strong binding affinity for HER3-HER2 heterodimers [33], and HER3 is an exceptionally strong activator of the PI3K cell survival axis, with six docking sites for PI3K's regulatory substrate p85 [34,35].

HER3 gene $(E R B B 3)$ amplification and overexpression are associated with resistance to a variety of cancer drugs, including chemotherapy, hormone therapy and trastuzumab [27,36-44]. With increasing recognition of its importance in therapeutic resistance, a variety of HER3-targeted agents are under development [45]. HER3's intracellular domain has low kinase activity and the conformational change required to engage p85 is dependent on transphosphorylation by other RTKs; predominantly, HER2. Hence, most agents typically target its ligand-binding domain or interfere with hetero-dimerization. There is accumulating data rationalising the testing of these agents in the brain-metastatic setting, however the relationships between receptor expression, activation and dimerization in human BM tumours have not been established.

In this study, we optimised a proximity ligation assay pipeline for detection and analysis of HER2-HER3 complexes in human BM tissue samples. We also tested the effects of trastuzumab and pertuzumab on the HER2/HER3 heterodimer landscape of HER2+ breast cancer cell lines provided with a saturating concentration of neuregulin-1. Our findings provide insight about the reduced intracranial efficacy of HER2-targeted agents.

\section{Materials and Methods}

\subsection{Cell Line Selection and Cell Culture}

Gene copy-number (Absolute), RNAseq $(\log 2 \mathrm{TPM}+1)$ and reverse phase protein array (RPPA) expression data for HER2 and HER3 were downloaded from depmap portal (Cancer 
Cell Line Encyclopaedia, Broad Institute $[46,47])$, and used to select four breast cancer cell lines for this study (Figure S1a). ERBB2 copy number alterations in these lines are all associated with complex chromosomal rearrangements [48]. MDA-MB-361, SKBr3, MCF7 and MDA-MB-231 were sourced from the American Type Culture Collection, maintained in a supplemented medium according to recommendations, and routinely checked for mycoplasma using the MycoAlert kit (Lonza), as described previously [49].

Cells were routinely cultured on glass coverslips to $70-80 \%$ confluence, followed by overnight culture in low-serum media (1\% foetal calf serum). For neuregulin assays, cells were cultured in low-serum medium supplemented with human NRG1 (R\&D systems; $50 \mathrm{ng} / \mathrm{mL}$; 'activation medium') for $30 \mathrm{~min}$. For antibody blocking experiments, serumdeprived cells were pre-incubated $(4 \mathrm{~h})$ with activation medium containing trastuzumab and/or pertuzumab (Roche, $20 \mu \mathrm{g} / \mathrm{mL}$; donated by the Royal Brisbane and Women's Hospital Pharmacy). Treated cells were rinsed with phosphate-buffered saline (PBS), fixed with paraformaldehyde (4\% in PBS) and permeabilised (0.5\% Triton X-100, 5 min).

\subsection{Clinical Samples and Human Research Ethics Committee Approval}

Two FFPE tissue microarray (TMA) cohorts were used in this study:

1. Mixed BM cohort: various histological origin: 48 from lung cancer, 33 breast, 30 melanoma, 19 renal cell, 17 colorectal, 5 prostate, 4 ovarian, 1 adenoid cystic, 1 neuroendocrine and 1 thyroid cancer case. HER2 status for these tumours was determined previously using immunohistochemistry (IHC) and diagnostic scoring criteria [30].

2. Breast-BM cohort: 41 brain-metastatic breast cancer cases (34 primary breast tumours and 44 BM, of which 28 are 'matched pairs') [31]. HER2 status was extracted from primary breast cancer pathology reports, determined by in situ hybridization (ISH).

TMAs were constructed by sampling tumour-rich regions from each tissue block in duplicate, as cores of $0.6-1.0 \mathrm{~mm}$ diameter. TMAs were sectioned $(4 \mu \mathrm{m})$ and dewaxed prior to heat-induced antigen retrieval (Table 1). After optimisation (Figure S1), PLA was performed as described for fixed cell lines, then sections were imaged with a Vectra 3 automated quantitative pathology imaging system (Perkin Elmer) at $20 \times$ magnification (emission/excitation: 461/359 nm (DAPI) and 618/590 nm (PLA)). Raw spectral image files (.im3) were spectrally unmixed to isolate individual channels and remove background autofluorescence prior to downstream image analysis.

Table 1. Primary antibodies, pairing, and optimised conditions.

\begin{tabular}{|c|c|c|c|c|c|c|c|c|c|}
\hline \multirow{2}{*}{$\begin{array}{c}\text { Dimer } \\
\text { Complex }\end{array}$} & \multicolumn{4}{|c|}{ Antibody 1 (Host: Rabbit) } & \multicolumn{4}{|c|}{ Antibody 2 (Host: Mouse) } & \multirow[b]{2}{*}{ Conditions * } \\
\hline & $\begin{array}{l}\text { Supplier } \\
\text { (Cat No.) }\end{array}$ & Clone & Host & Dilution & $\begin{array}{l}\text { Supplier } \\
\text { (Cat No.) }\end{array}$ & Clone & Host & Dilution & \\
\hline \multicolumn{10}{|c|}{ In vitroExperiments (Fixed Cells on Coverslips) } \\
\hline $\begin{array}{l}\text { (1)HER3- } \\
\text { (2)EGFR }\end{array}$ & $\begin{array}{c}\text { CST } \\
(12708)\end{array}$ & $\mathrm{D} 22 \mathrm{C} 5$ & Rabbit & $1 / 100$ & $\begin{array}{c}\mathrm{SC} \\
(\mathrm{sc} 73511)\end{array}$ & $\mathrm{R} 2$ & Mouse & $1 / 500$ & $\mathrm{O} / \mathrm{N}, 4{ }^{\circ} \mathrm{C}$ \\
\hline $\begin{array}{l}\text { (1)HER3- } \\
\text { (2)HER2 }\end{array}$ & $\begin{array}{c}\text { CST } \\
(12708)\end{array}$ & $\mathrm{D} 22 \mathrm{C} 5$ & Rabbit & $1 / 100$ & $\begin{array}{c}\text { Abcam } \\
\text { (ab16901) }\end{array}$ & 3B5 & Mouse & $1 / 2000$ & $\mathrm{O} / \mathrm{N}, 4^{\circ} \mathrm{C}$ \\
\hline $\begin{array}{l}\text { (1)HER3- } \\
\text { (2)HER4 }\end{array}$ & $\begin{array}{c}\text { CST } \\
(12708)\end{array}$ & $\mathrm{D} 22 \mathrm{C} 5$ & Rabbit & $1 / 100$ & $\begin{array}{c}\text { SC } \\
\text { (sc-71070) }\end{array}$ & 3F168 & Mouse & $1 / 100$ & $\mathrm{O} / \mathrm{N}, 4^{\circ} \mathrm{C}$ \\
\hline $\begin{array}{l}\text { (1)HER2- } \\
\text { (2)EGFR }\end{array}$ & $\begin{array}{l}\text { DAKO } \\
\text { (A0485) }\end{array}$ & Poly & Rabbit & $1 / 2500$ & $\begin{array}{c}\mathrm{SC} \\
(\mathrm{sc} 73511)\end{array}$ & $\mathrm{R} 2$ & Mouse & $1 / 500$ & $\mathrm{O} / \mathrm{N}, 4^{\circ} \mathrm{C}$ \\
\hline $\begin{array}{l}\text { (1)HER2- } \\
\text { (2)HER4 }\end{array}$ & $\begin{array}{l}\text { DAKO } \\
\text { (A0485) }\end{array}$ & Poly & Rabbit & $1 / 2500$ & $\begin{array}{c}\text { SC } \\
\text { (sc-71070) }\end{array}$ & 3F168 & Mouse & $1 / 100$ & $\mathrm{O} / \mathrm{N}, 4^{\circ} \mathrm{C}$ \\
\hline \multicolumn{10}{|c|}{ In situ Analysis (FFPE Tissue Sections) } \\
\hline $\begin{array}{l}\text { (1)HER2- } \\
\text { (2)HER3 }\end{array}$ & $\begin{array}{l}\text { DAKO } \\
\text { (A0485) }\end{array}$ & Poly & Rabbit & $1 / 2500$ & MP (05-390) & $2 \mathrm{~F} 12$ & Mouse & $1 / 200$ & $\begin{array}{c}10 \mathrm{mM} \\
\text { Tris-EDTA } \\
(\mathrm{pH} 8.8) 95^{\circ} \mathrm{C} \text {; } \\
30^{\prime} \mathrm{O} / \mathrm{N} 4^{\circ} \mathrm{C}\end{array}$ \\
\hline
\end{tabular}


All samples in this study pre-date the use of pertuzumab for metastatic breast cancer. This study was approved by human research ethics committees of the National Hospital for Neurology and Neurosurgery (London, UK; mixed BM TMA construction), the Royal Brisbane and Women's Hospital and The University of Queensland (Queensland, Australia; matched TMA construction and molecular analysis of both cohorts).

\subsection{Immunofluorescence}

Antibodies were selected based on manufacturer guarantee and/or published evidence of specificity (Table 1). We then optimised detection conditions using immunofluorescence. For fixed cells on coverslips, non-specific binding sites were blocked $(10 \%$ goat serum in PBS) for $30 \mathrm{~min}$, then samples were incubated with primary antibodies in blocking buffer (Table 1) for $1 \mathrm{~h}$ at room temperature. After rinsing with PBS, detection was performed with Alexa Fluor ${ }^{\mathrm{TM}}$ 488-conjugated, species-specific secondary antibodies (\# A28175, \#A11012, Thermofisher, Waltham, MA, USA) diluted 1:400 in blocking buffer (30 min, room temperature). Samples were washed with PBS, counterstained with DAPI and mounted (Prolong Gold, \#MAN0009669, Thermofisher, Waltham, MA, USA). For formalin-fixed, paraffinembedded (FFPE) samples, sections were subjected to heat-induced antigen retrieval prior to immunofluorescent staining (Table 1).

\subsection{Fluorescent In Situ Proximity Ligation Assay (PLA)}

PLA was carried out in humidified slide chambers, according to the technical protocol and kit reagents supplied (Duolink In Situ Red Starter Kit Mouse/Rabbit, \#DUO92101, Sigma Aldrich, St. Louis, MO, USA). Briefly, non-specific antibody binding sites were blocked for $1 \mathrm{~h}$ at $37^{\circ} \mathrm{C}$, then samples were incubated with primary antibodies raised in different host species (Table 1). For detection of dimer complexes, oligonucleotideconjugated, species-specific secondary antibodies (supplied in the Duolink kit) were applied ( $1 \mathrm{~h}$, room temperature), followed by ligase and ligation oligonucleotides $\left(30 \mathrm{~min}, 37^{\circ} \mathrm{C}\right)$ to catalyse the circularization of complementary probes bound within approximately $40 \mathrm{~nm}$. Fluorescent labelled oligonucleotides and polymerase were then added $\left(100 \mathrm{~min}, 37^{\circ} \mathrm{C}\right)$, for "rolling-circle" amplification of dimer signals, generating a quantifiable fluorescent red spot [50]. After amplification, samples were counterstained with DAPI, and coverslips were mounted on glass slides (Prolong Gold, \#MAN0009669, Thermofisher, USA). Fifteen randomly selected microscopic fields from each sample were imaged at 20x magnification (Zeiss Axio Imager M1, Carl Zeiss, Jena, Germany), generating a .czi file for each region-ofinterest (ROI).

\subsection{Digital Image Analysis}

We developed a pipeline to automate the extraction of PLA data from fluorescent images. It uses two freely available bioimaging analysis software packages: QuPath (v 0.1.2), which has algorithms for nuclear identification, cell counting and batch analysis [51]; and ImageJ; specifically the "Find Maxima" plugin, which we found to be superior to other alternatives for differentiating true fluorescent foci (signals) from noise. With slightly different steps for fixed cells and tissue samples, this pipeline is depicted in Figure 1, and a detailed protocol with all the required scripts are provided as Supplementary Data.

Image files were loaded into QuPath (we used .czi files, though Qupath will accept other formats). An optimized cell detection algorithm was then applied on the blue channel (DAPI) to detect cells based on nuclear size and fluorescence intensity. Files were then exported to ImageJ where the optimized Find Maxima algorithm was applied to detect dimer signals in the red channel in the form of Alexa Fluor ${ }^{\mathrm{TM}}$ 594-positive foci. For FFPE tissue sections, tumour-rich ROIs were first annotated manually with the aid of matching hematoxylin and eosin-stained, serial sections, with cell and PLA signal detection restricted to these ROIs. 


\begin{tabular}{|c|c|c|c|c|}
\hline & & SKBr3 & MDA361 & MCF7 \\
\hline \multirow{3}{*}{ HER2 } & Copy-number & amp & amp & del \\
\hline & Baseline exp & high & average & low \\
\hline & Baseline act. & high & average & low \\
\hline \multirow{3}{*}{ HER3 } & Copy-number & high gain & gain & diploid \\
\hline & Baseline exp & average & low & average \\
\hline & Baseline act. & average & low & average \\
\hline \multicolumn{2}{|c|}{ Relevant mutations } & $\begin{array}{l}\text { ERBB33E952Q } \\
\text { PTEN }^{\text {del }}\end{array}$ & $\begin{array}{l}\text { PIK3CA } \\
\text { PIK } 3 C 45 A^{\text {K567R }} \\
\text { AKT1 }{ }^{\text {D3N }}\end{array}$ & PIK3CA ${ }^{E 545 K}$ \\
\hline
\end{tabular}
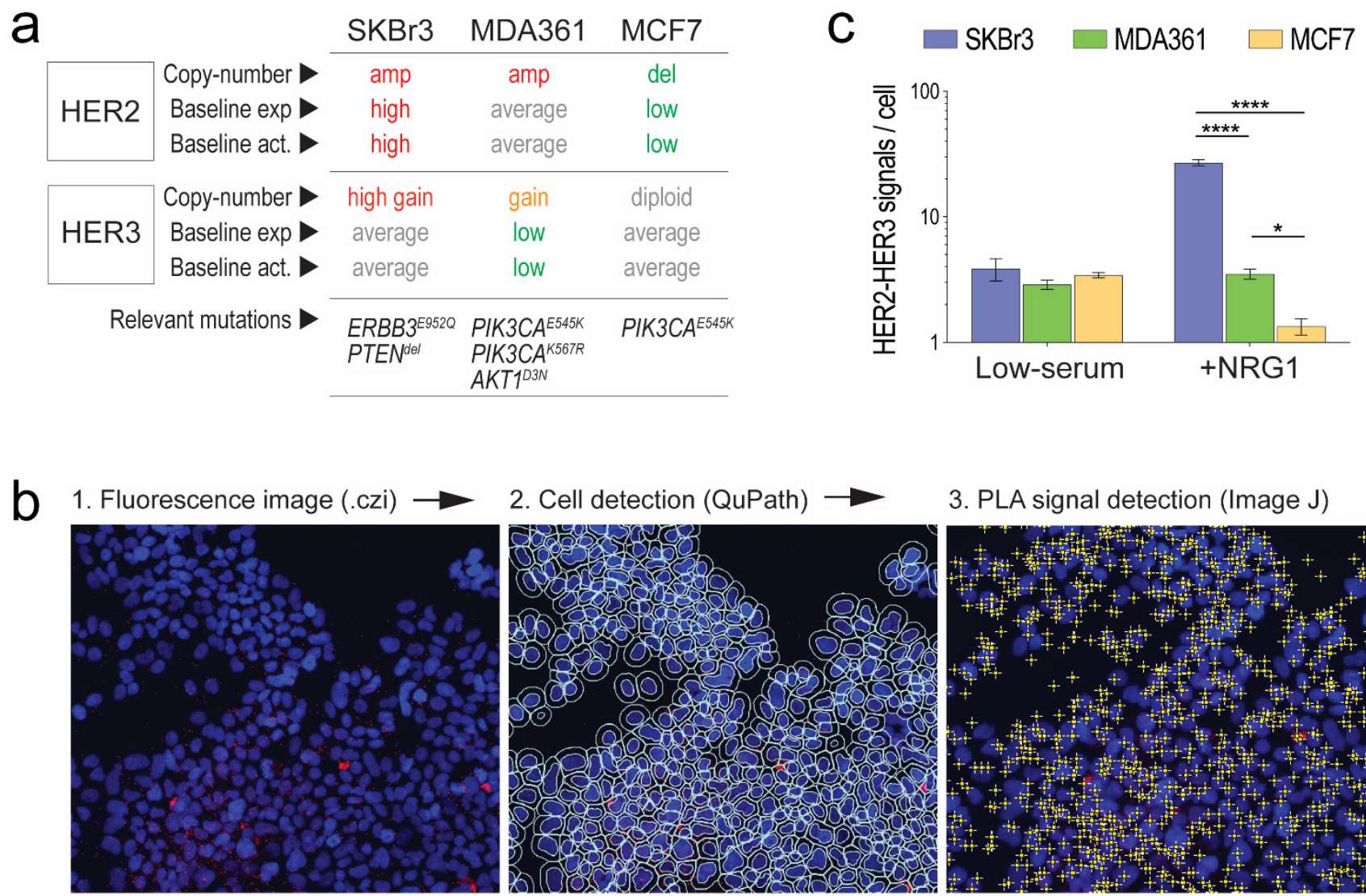

3. PLA signal detection (Image J)

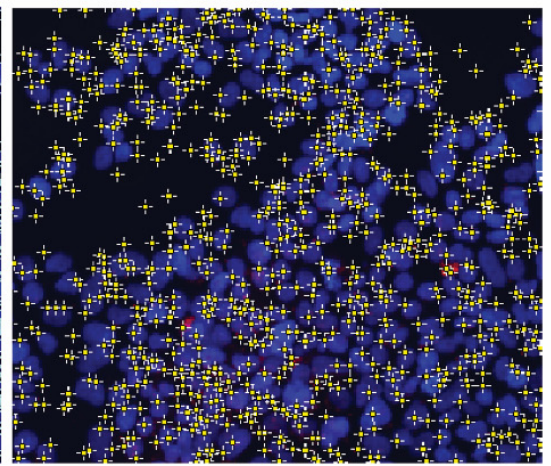

Figure 1. Validation of fluorescent in situ PLA and data extraction pipeline. (a) Gene copy number, baseline exp(ression) and act(ivation) status and relevant pathway mutations for the cell lines used. (b) Summary of data extraction steps (see methods and Supplementary Information). (c) Comparative analysis of HER2-HER3 complex signals across cell lines in low-serum or NRG1-supplemented media ${ }^{* * * *} p<0.0001 ;{ }^{*} p<0.05$; Fisher's LSD test). $20 \times$ magnification.

After verifying the accuracy of this process on test images, we developed a high throughput batch-processing approach to parse hundreds of files (Supplementary Data). PLA data can be expressed as signals /cell, and/or signals per unit area. We used Prism 8 (GraphPad, v9.2) for statistical analyses (specific tests and p-values indicated in the respective figure legends).

\section{Results}

\subsection{Validation of Fluorescent In Situ PLA and Development of a Data Extraction Pipeline}

We optimised a PLA protocol using breast cancer cell lines with differing HER2 and HER3 activation status, and relevance to human BM [46,47] (Figure 1a and Figure S1a):

- $\quad$ SKBr3, a model of genomically driven HER2-HER3-PI3K pathway activation with $E R B B 2$ and $E R B B 3$ copy-number gains, high expression, and strong activation under baseline culture conditions, a HER3 tyrosine kinase domain mutation of unknown significance, and homozygous deletion of PTEN. PTEN exerts negative feedback on PI3K and is frequently lost in breast cancer BM [30,52,53].

- $\quad$ MDA(-MB-)361, a breast cancer BM-derived line with ERBB2 and ERBB3 gene copynumber gains but average to low baseline expression and activation. This line has dual PIK3CA mutations (E545K, K567R): helical domain alterations that decouple PI3K's catalytic and regulatory domains, disrupting negative feedback [54-56]. Its growth in the brain is more dependent on PI3K and HER3 than HER2 [27].

- $\quad$ MCF7, a model of luminal-like breast cancer with below average baseline expression and activation of HER2 and HER3, ERBB2 copy number loss and PIK3CA ${ }^{E 545 K}$. 
After optimising detection conditions for the chosen anti-HER antibodies (Table 1 and Figure S2), we performed PLA analysis on these cell lines before and after treatment with neuregulin-1 (NRG1) to verify the expected frequencies of HER2-HER3 complexes. As a typical experiment involves acquiring and counting foci from at least 10 regions-of-interest (ROIs) per sample, we developed a pipeline to streamline and automate the extraction of PLA data from image files (Figure 1b). This experiment showed that HER2-HER3 complexes were detectable in low-serum conditions, with negligible differences between SKBr3, MDA361 and MCF7 cells. However, 30 min after NRG1 treatment, there were marked differences consistent with the genomic and expression status of HER2 and HER3 in these lines (Figure 1c). These data indicated that with further optimisation, this pipeline should be suitable for analysis of human clinical samples.

\subsection{HER2-HER3 Complexes Are Prevalent in Brain Metastases with Different Histological Origins, but Do Not Correlate Reliably with Protein Level or Phosphorylation}

HER2 and HER3 are induced and activated in BM, but the frequency of dimer complexes in relation to expression and activation has not been assessed. This is relevant because HER2-HER3 dimerization is therapeutically targetable with pertuzumab, but there have been no clinical studies directly testing its intracranial efficacy. We adapted the PLA pipeline for FFPE tissue sections, first optimising detection conditions (Figure 2a), then adding a tissue segmentation step that restricts cell and PLA signal counting to tumour-rich ROIs (Figure 2b). We quantified tumour-specific PLA signals per unit area and found a very strong correlation with signals per cell (in cross-section), hence either method would convey the same information for highly cellular ROIs (Figure 2c).

Next, we applied the PLA pipeline to a human tumour sample cohort comprising BM from breast, lung, kidney, colorectal, ovarian, skin (melanoma) and prostate cancers. PLA signals were clearly detectable across the sample cohort, albeit at lower frequency than in vitro experiments as analysis was based on $4 \mu \mathrm{M}$ tissue sections versus whole cells.

There were 159 assessable cases, which we referenced against histologically normal tissue samples that were processed in parallel (lymph node, kidney, and colon, which express HER3 but not HER2 [57]). Data were extracted from an average of 3989 cells per sample (range 382-13,704), corresponding to an average ROI area of $350 \mu \mathrm{m}^{2}$ (range 30-830 $\mu \mathrm{m}^{2}$ ). BMs from melanoma, kidney, lung, ovarian and breast cancers had significantly more frequent HER2-HER3 dimers than normal reference tissues ( $p \leq 0.01$ by Kruskal-Wallis test; Figure 2d). Breast cancer BMs had the highest frequency, though the levels in ovarian, lung and kidney cancer BM were only marginally lower $(p>0.01$ by Kruskal-Wallis test). Levels were lowest in the prostate cancer BMs, consistent with other reports that HER receptor expression is relatively low in prostate cancers [58,59].

Separating breast and lung cancers according to HER2 status highlighted that on average, HER2+ BM had significantly more HER2-HER3 dimers than negative or equivocal cases (Figure 2e). A total of 48.5\% (16/33) and 14.6\% (7/48) of breast and lung BMs in this cohort were HER2+. However, the HER2-HER3 dimer frequency in HER2+ tumours was not consistently higher (Figure 2d), suggesting that HER2 IHC is not a reliable indicator of HER2-HER3 dimerization. How this relates to the efficacy of pertuzumab is currently unknown.

Finally, we determined whether HER2-HER3 dimer frequency is reflected by the extent of HER2 and HER3 phosphorylation in the breast and lung cancer BMs, by correlating PLA data with pHER2 and pHER3 IHC data that we published previously from this cohort [30]. There were indeed positive associations, particularly for breast cancer BM, but these trends were largely driven by the HER2+ cases (Figure 2f). This suggests that like HER2 status, the extent of HER2 and HER3 activation evident by IHC is also not a reliable indicator of HER2-HER3 dimer frequency in BM. 

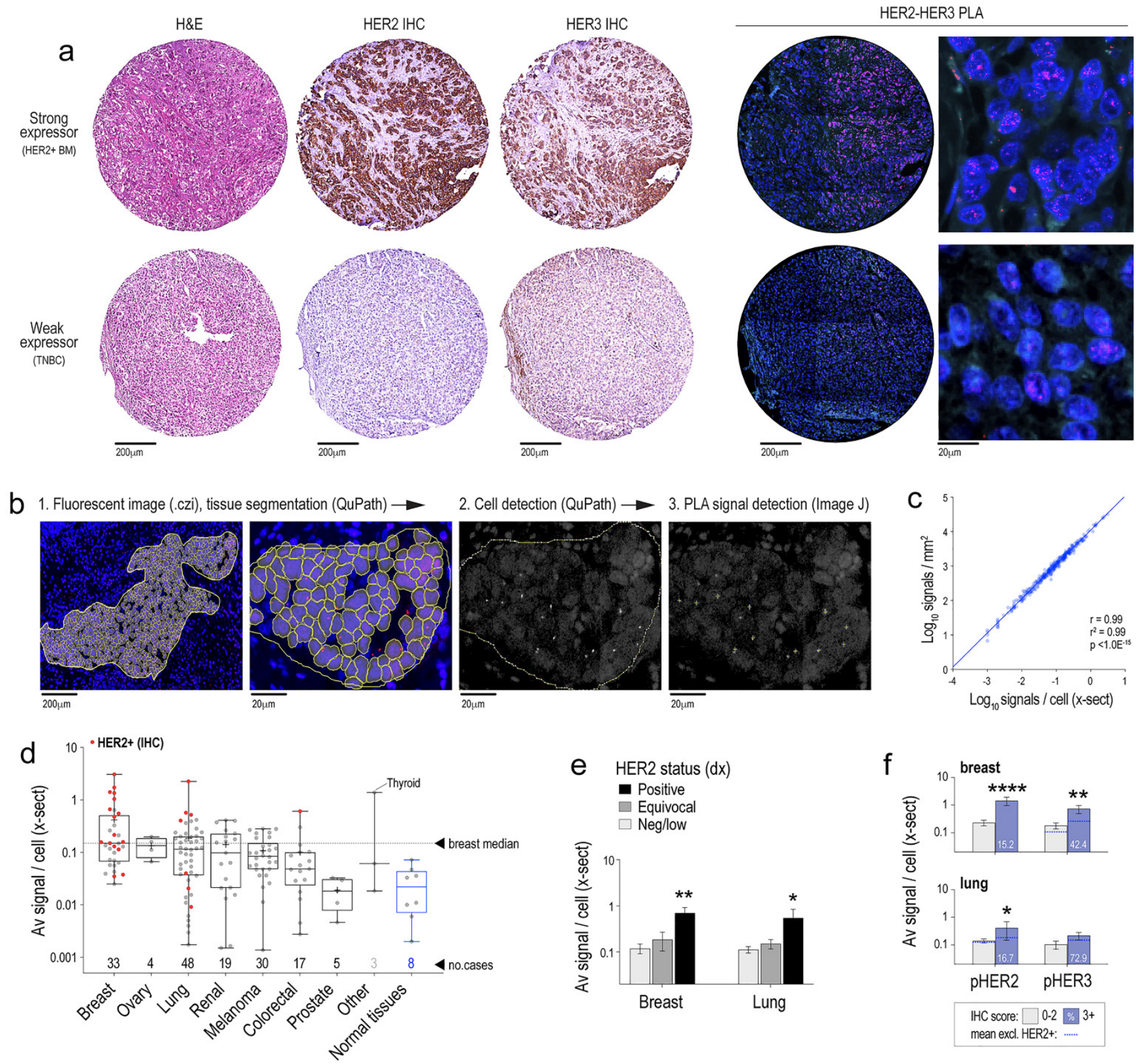

Figure 2. Quantification of HER2-HER3 dimers in a mixed cohort of human brain metastases. (a) Representative images from matching TMA cores stained with haematoxylin and eosin (H\&E), HER2 or HER3 IHC protocols, or the HER2-HER3 PLA protocol. (b) Summary of data extraction steps (see methods and Supplementary Information). (c) Correlation between PLA signals as a function of tissue area or cell number (Spearman correlation (r), goodness of fit $\left(\mathrm{r}^{2}\right)$ and $\mathrm{p}$-value indicated). (d) Comparative analysis of HER2-HER3 signal frequency in BM according to primary histology. Cases classified as HER2+ using diagnostic IHC criteria are shown in red. (e) Comparison of HER2-HER3 signal frequency in breast and lung cancer BM classified HER2+, equivocal (2+) or negative-low. (f) Relationships between HER2-HER3 signal frequency in breast and lung cancer BM with strong activation of HER2 or HER3 (pHER2/ pHER3 3+ by IHC) versus negative to moderate activation (0-2+). Dotted blue lines: average signal frequency excluding HER2+ tumours. Fisher's LSD tests were used for e-f (reference: neg/low groups; ${ }^{*} p<0.05,{ }^{* *} p<0.01,{ }^{* * * *} p<0.0001$ ).

\subsection{HER2-HER3 Dimers Are Induced in BM Compared to Matched Primary Breast Tumours}

HER2 and HER3 are induced and activated in BM, however changes in HER2-HER3 dimer frequency after metastasis to the brain has not been directly assessed. We investigated 
this using PLA analysis of a unique cohort of breast cancer BM with patient-matched primary breast tumours, arrayed in TMA format [31]. There were 76 assessable tumour samples from 41 patients, including 28 matched pairs.

Overall, HER2-HER3 signal frequency was significantly higher in BMs compared to breast tumours (Mann-Whitney $p=2.1 \times 10^{-4}$; Figure 3a). The difference in HER2-HER3 signals between matched primary breast and BM cases were calculated as fold-change and compared. Separating the matched pairs into subtypes defined by ER, PR and HER2 status showed average increases of 17.5, 5.9 and 2.3-fold for HER2+, triple-negative and $\mathrm{ER}+$ cases, respectively (Figure $3 \mathrm{~b}$ ). In terms of case numbers, this represents increases of more than 2-fold for 11/14 (79\%) HER2+ cases, 4/9 (44\%) triple-negative cases and 3/4 $(75 \%)$ ER+ cases. There was no statistical difference between the groups. For the HER2+ cases, 6 samples ( 4 patients) were from patients treated with trastuzumab prior to BM resection, and 8 were from patients who were naïve to HER2-targeted therapy at the time of BM resection. There was a marginal difference between these groups, with HER2-HER3 complexes more frequent overall in pre-treated tumours ( $p=0.1$; Figure $3 c)$.
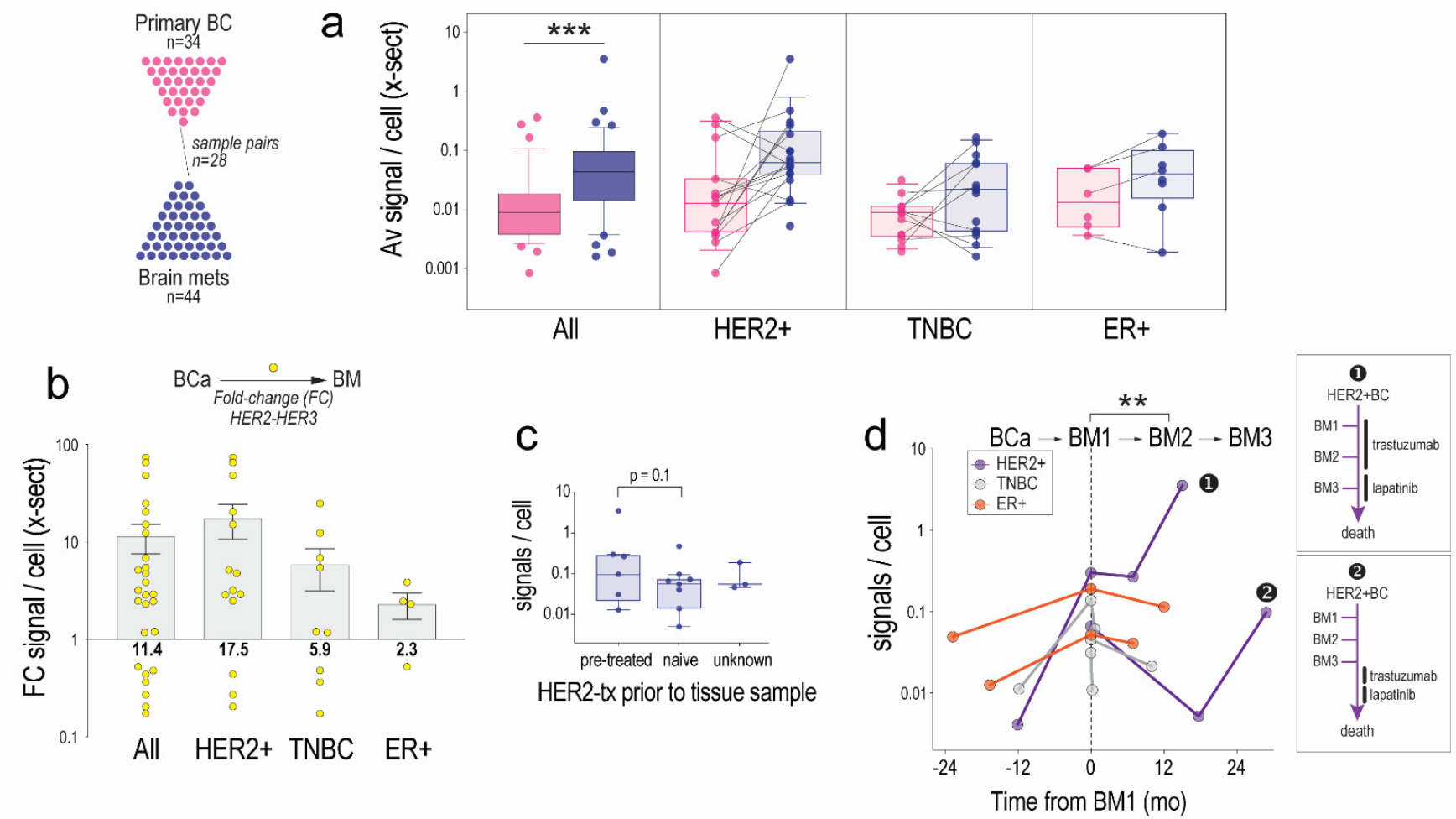

Figure 3. Analysis of HER2-HER3 dimers in brain metastatic breast tumours and breast cancer BM. (a) Average HER2-HER3 signals per cell for the entire cohort (all), and disease subtypes (MannWhitney, $\left.{ }^{* * *} p=2.1 \times 10^{-4}\right)$. (b) Fold-change (FC) dimer signals between the primary and BM samples of 28 matched pairs (mean \pm standard error shown. (c) Relationship to HER2-targeted treatment (tx). Marginally higher HER2-HER3 dimer frequency in pre-treated vs. treatment-naïve HER2+BM ( $p=0.1$; 2-tailed $t$-test). (d) HER2-HER3 dimer frequency differences between first (BM1) and subsequent (BM2, BM3) brain recurrences for seven patients who had more than one neurosurgical resection procedure. Insets show the timing of HER2-targeted therapy with respect to BM1/2/3 samples. HER2-HER3 dimer frequency in BM2 was lower than the BM1 group (paired, 2-tailed test, ${ }^{* *} p<0.01$, $* * *<0.001)$.

For the 7 patients who had more than one BM resected, we were also able to quantify changes between successive brain tumours. Interestingly, dimer frequency was lower for second recurrences ( $p=0.006$; Figure $3 \mathrm{~d}$ ). The average interval between BM1 and BM2 in this cohort was just under 8 months (interval range $0.2-17.7$ months). Two patients in this 
group had their BM1 and BM2 craniotomy procedures less than a month apart, hence their BM1 and 2 samples were more likely to be from synchronous than sequential recurrences, but even after excluding these patients ( $n=5$, interval 7-17.7 months), the decrease in HER2-HER3 dimer frequency between BM1 and BM2 was still apparent $(p=0.02)$.

For the two HER2+ patients in this group, there were substantial increases in dimer frequency between the second and third events, regardless of prior treatment with HER2targeted therapy: patient-1 (very high HER2-HER3 in BM3) was heavily pre-treated, while patient-2 (high HER2-HER3 in BM3) was not treated with trastuzumab and lapatinib until after neurosurgical resection (Figure $3 \mathrm{~d}$ ).

\subsection{Effects of HER2-Targeted $m A$ bs on the HER2/3 Heterodimer Landscape}

Next, we investigated the effects of trastuzumab (Tz) and pertuzumab (Pz) on HER2 and HER3 heterodimer configurations, under controlled experimental conditions. We used our in vitro PLA pipeline to quantify five different complexes in SKBr3 and MDA361 cells-both ERBB2-amplified but with different pathway alterations and drivers. In HER2-3 driven SKBr3 cells, NRG1 induced substantial changes in the dimer landscape, marked by increases in HER2 dimerization with NRG1 receptors HER3 and HER4 ( 7-fold), at the expense of HER3-EGFR complexes (reduced by 32-fold; Figure 4a). A similar response was seen in PI3K-dependent MDA361 cells, though at a lower magnitude (Figure 4a).

Next, we incubated the cells with Tz and/or Pz prior to NRG1 stimulation, to quantify changes in the dimer landscape in the context of neuregulin saturation. Interestingly, in $\mathrm{SKBr} 3$ cells this did not reduce the frequency of any of the complexes, instead increasing all dimers except HER2-HER3 (Figure 4b). This was observed for mAb-treated cells even in the absence of NRG1 (Figure S3). However, changes in the individual complexes were inconsequential to the overall distribution (Figure 4c). For instance, Pz and Pz+Tz induced significant increases in HER3-HER4 dimerization, but this complex was very infrequent in SKBr3 cells compared to HER2-HER3 and HER2-HER4. In summary, NRG1-stimulation significantly increased the levels and relative proportions of HER2-HER3 and HER2-HER4 complexes, and this distribution was relatively unperturbed by $\mathrm{Tz}$ and $\mathrm{Pz}$.

MDA361 cells are ERBB2-amplified but not fully dependent on HER2, owing mutated PI3K that is constitutively active and decoupled from RTK feedback. Pre-treatment of this line with $\mathrm{Tz}$ and/or Pz produced modest but statistically significant changes in HER2/3 dimer frequency, notably including suppression of NRG1-induced HER2-HER3 dimerization by $\mathrm{Tz}+\mathrm{Pz}$ (Figure $4 \mathrm{~b}$ ), resulting in HER2-HER4 dimers having a slightly more dominant presence in the overall dimer distribution (Figure 4c). We performed the NRG1 and $\mathrm{mAb}$ treatments on a second occasion to verify the reproducibility of the PLA results and our conclusions (Figure S3b). 

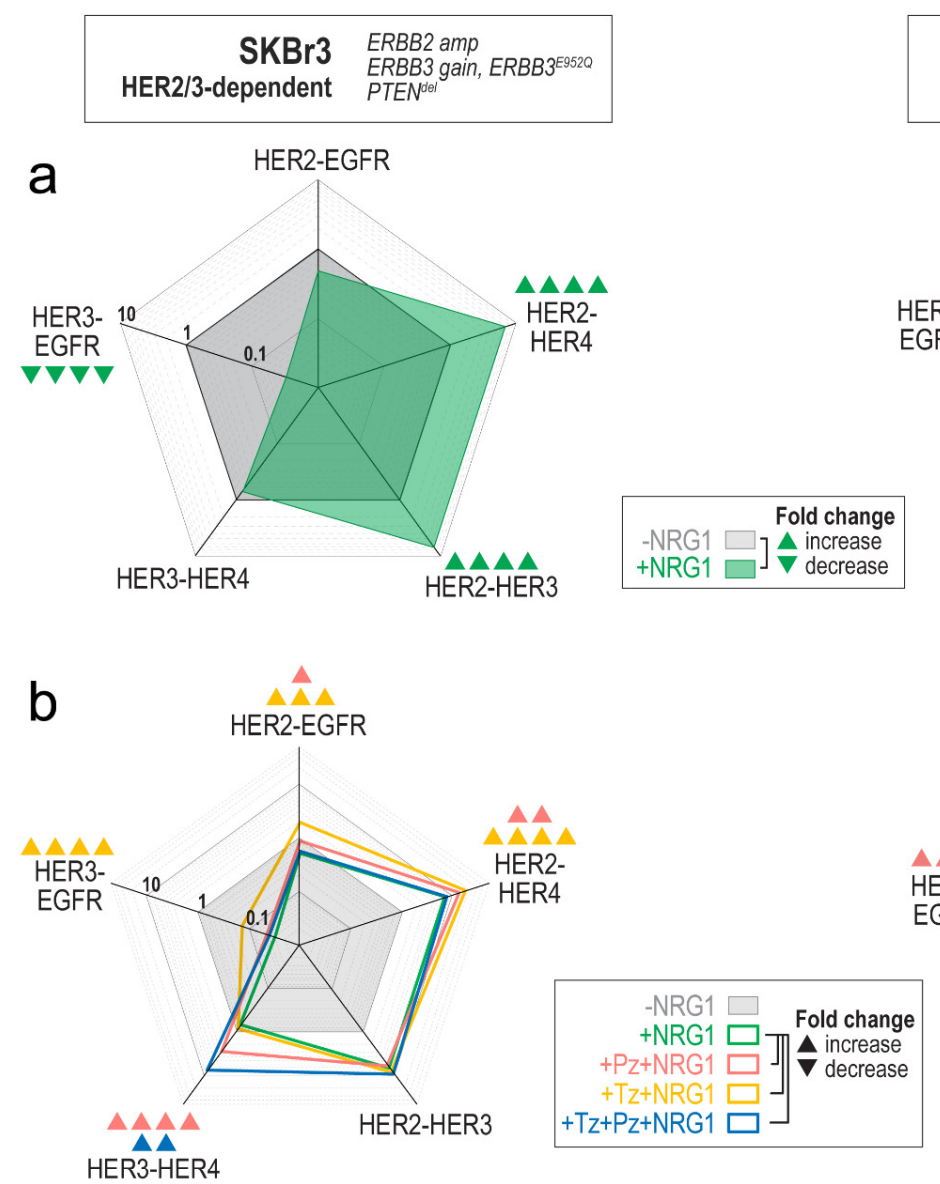
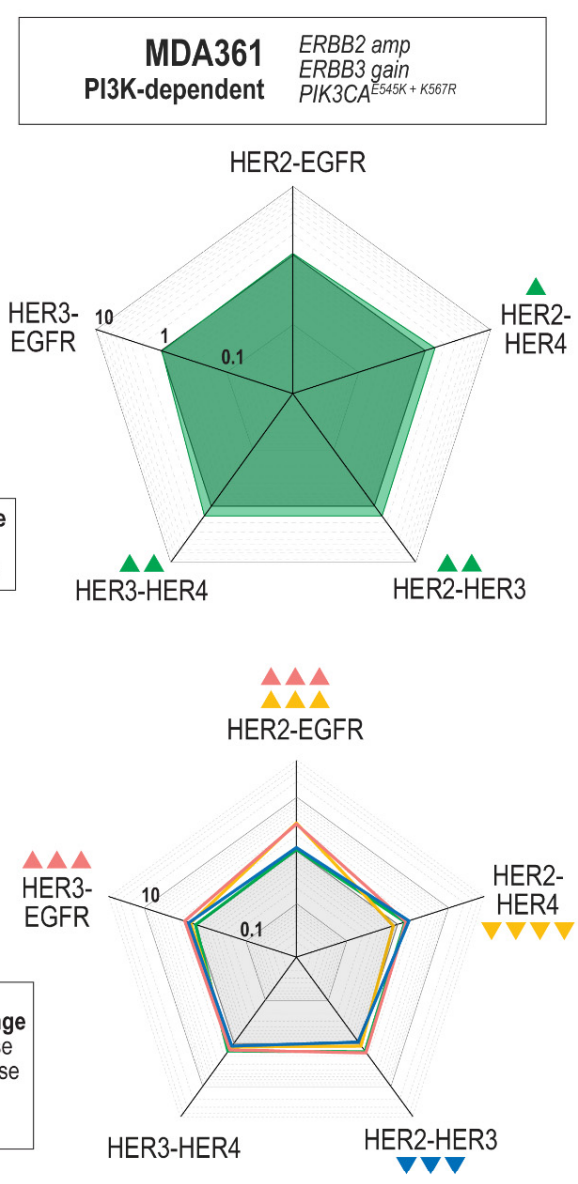

C
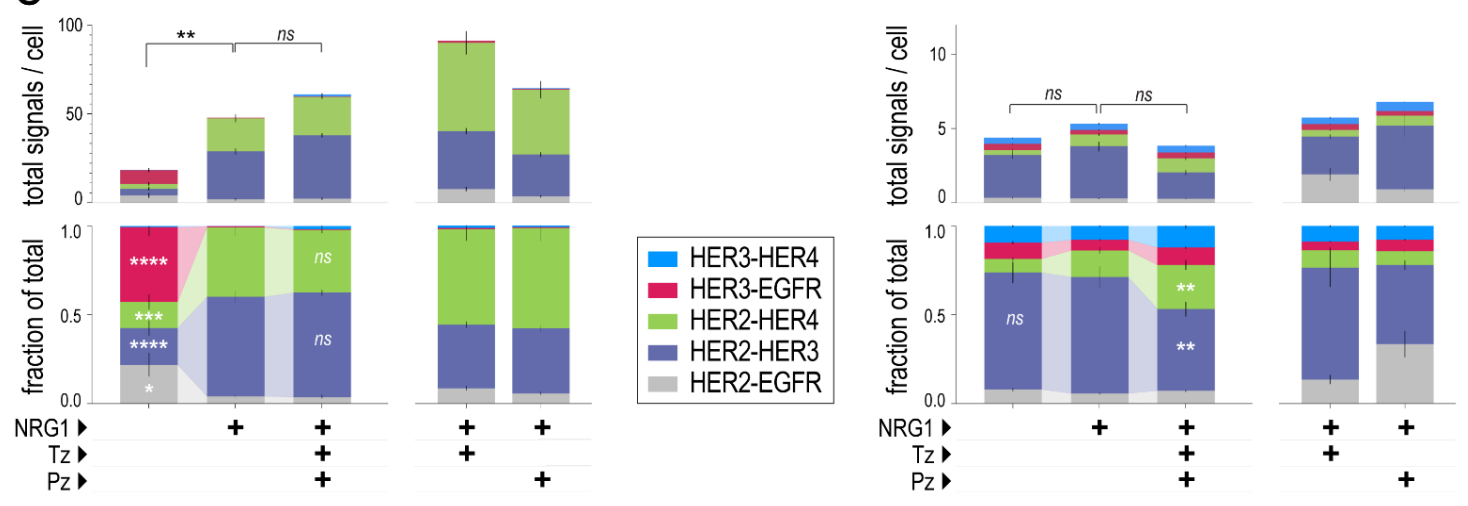

Figure 4. Effects of neuregulin-1, trastuzumab and/or pertuzumab on the HER2/HER3 heterodimer landscape. (a) NRG1-induced dimerization in SKBr3 or MDA361 cells (radar plots show fold change). Arrows indicate the direction of change relative to untreated cells ( $\boldsymbol{\Delta}$ increase, $\mathbf{\nabla}$ decrease), where the change was at least 1.5-fold with $p<0.05$ by 2-tailed $t$-test $(\boldsymbol{\Lambda} \mathbf{\Lambda} \boldsymbol{\Lambda} \mathbf{\Lambda}, p<0.0001, \mathbf{\Lambda} \mathbf{\Lambda} \mathbf{\Lambda}, p<0.001$; $\boldsymbol{\Delta} \mathbf{\Lambda}, p<0.01 ; \mathbf{\Lambda}, p<0.05$ ). (b) NRG1-induced fold change in dimer frequency in the presence of trastuzumab $(\mathrm{Tz})$ and/or pertuzumab $(\mathrm{Pz})$. Arrows indicate the direction of change relative to the + NRG1 reference, where the change was at least 1.5-fold with $p<0.05$ (2-tailed $t$-test, arrow markers as for (a)). (c) Changes in the overall distribution of the five complexes in the presence of NRG1, Tz and Pz. Data shown are means +/ - standard error, expressed as either absolute (top) or fractional (bottom) dimer signals. Significant changes are highlighted, where changes were $\pm 10 \%$ of the reference (+NRG1), with $p<0.05$ by 2-tailed $t$-test: ${ }^{* * *} p<0.0001,{ }^{* * *}, p<0.001 ;{ }^{* *}, p<0.01$; $*, p<0.05 ; n s$, not significant). Changes with individual mAbs are shown for comparison. 


\section{Discussion}

In this study, we used an optimised proximity ligation assay and analysis pipeline to quantify the levels of therapeutically targetable HER2-HER3 dimers in human BM, and the effect of HER2-targeted mAbs on HER2/3 heterodimer complexes in vitro. There were several key findings. As expected, HER2-HER3 dimers were generally more frequent in BM classified as HER2+, but this was not a particularly reliable indicator, as some brain metastases had a high frequency of HER2-HER3 complexes regardless of HER2 status, and conversely, some tumours classified as HER2+ had relatively lower levels. This may be considered a recent finding that HER2-low breast cancers metastasise to the brain at a frequency between that of HER2-negative and -positive tumours [60].

Our analysis of a second, clinically annotated breast cancer BM cohort showed that BM had a higher overall frequency of HER2-HER3 dimers compared to brain-metastatic primary tumours (particularly HER2+ cases, but not exclusively). Interestingly, a subgroup analysis of patient-matched, successive BM showed that HER2-HER3 complexes were significantly less frequent in subsequent recurrences. We do not know the clonal relationships between the first and second BM, but if the latter arose by BM self-seeding, this could suggest there is less selection pressure to maintain HER2-HER3 signalling after initially colonising the brain.

BM from patients previously treated with HER2-targeted therapy had higher HER2HER3 dimer levels than treatment-naïve tumours. This trend was modest in our exploratory case series $(p=0.1)$, but given that most HER2+ breast cancer patients are now treated in the first-line setting with trastuzumab and pertuzumab, and that intracranial disease is relatively insensitive to HER2 therapy [12-16], larger cohort studies would be warranted to investigate HER2-HER3 dimerization in relation to acquired resistance, and whether this can be suppressed by pertuzumab and/or anti-HER3 mAbs in the metastatic setting. The NRG-HER3-HER2 axis has been strongly implicated in HER2+ breast cancer relapse $[10,17,27,30,32,61]$, and preclinical studies have shown that pertuzumab and LJM716 (HER3-inactivating mAb) significantly reduce the outgrowth of experimental HER2+BM [27]. Further clinical development of LJM716 is underway [62,63], though it is unclear if planned clinical trials will assess intracranial progression as a specific endpoint.

Our in vitro experiments suggested that in the context of neuregulin oversupply, trastuzumab and pertuzumab are not particularly effective at reducing HER2-HER3 dimerization. HER2 dimerization blockade is pertuzumab's primary mode of action, and yet the association between neuregulin-1 and the HER2-HER3 complex is about two orders of magnitude stronger than that between pertuzumab and HER2 (equilibrium dissociation constants $\left(\mathrm{K}_{\mathrm{D}}\right) 0.02$ vs. $2.5 \mathrm{nM}$, respectively $\left.[33,64]\right)$. Schwarz and colleagues found that induction of neuregulin-1 and autocrine activation of HER3-PI3K mediates acquired resistance to T-DM1 in HER2+ breast cancer xenografts [61]. In our experiments, HER2-HER3 and HER2-HER4 remained the predominant heterodimer complexes in the presence of NRG1, Tz and Pz. We previously reported frequent co-expression of pHER3 and pHER4 in BM [30,31]. Together with the well-known functional redundancy in the HER family, and frequent alterations in PTEN and PI3K in BM [30,52,53,65], these observations may help to explain their efficient acquisition of resistance to existing targeted agents.

PLA likely captures receptor clusters within organised membrane signalling patches as opposed to individual dimer complexes [66,67], therefore should be regarded as semiquantitative. Nevertheless, for relative quantification, it is still a biologically and functionally relevant readout of dimer frequency. This study was not without limitations, and independent analyses would help to corroborate our conclusions; particularly studies that characterise dimer heterogeneity and establish whether particular HER2 or HER3 complexes predict pertuzumab efficacy in animal models or clinical trial biospecimens.

It would be of great interest to include HER3 homodimers in such studies, which we were unable to analyse because the PLA protocol is not suitable for homodimer analysis. This is because PLA relies on two different species-specific primary antibodies that are at proximity to detect protein-protein interactions. Unless the pair of antibodies are 
specific against the same epitope, it is not possible to exclude that the PLA signals from two antibodies against the same protein reflect overall protein expression. In vitro single particle tracking studies indicated that HER3 homodimers are more stable than HER2HER3, and that multiple signalling-competent HER3 homodimers could be catalysed by a single HER2-mediated transphosphorylation event, making HER3-PI3K activity less reliant on equivalent levels of other dimerization partners [66]. If found to be prevalent in BM, this would have important implications for therapeutic development and clinical trial design.

\section{Conclusions}

Coupled with automated digital image analysis, the PLA workflow described here is a straightforward, accurate technique for relative quantification of HER family heterodimers in both cell lines and FFPE tissue samples. Our application of this pipeline to annotated clinical samples showed that HER2-HER3 complexes are prevalent and induced in BM, but not reliably related to HER2 amplification, expression or activation, raising questions about whether these biomarkers would be relevant predictive indicators in BM. To resolve this, preclinical HER-targeted drug efficacy studies may benefit from including dimer quantification as a covariate.

Importantly, we found that trastuzumab and pertuzumab had minimal impact on the HER2/3 heterodimer landscape in the context of neuregulin oversupply; a unique feature of brain tissue that we simulated by supplementing HER2+ cell cultures with recombinant protein. Our results suggest that neuregulin-1 could compete with HER2 dimerisation blockers by virtue of its high affinity for the HER2-HER3 complex. Hence, in the setting of brain-metastatic disease, antibody-drug or -radiotherapeutic conjugates that target nonspecific payloads to these receptors, rather than relying on signalling blockade, may be favourable to conventional agents. More preclinical studies in this area are warranted.

Supplementary Materials: The following supporting information can be downloaded at: https: / / www.mdpi.com/article/10.3390/cancers14030533/s1, Figure S1: Cell line selection, Figure S2: Validation of antibodies, Figure S3: In vitro PLA data supporting, Supplementary Data: QuPath script used for batch analysis.

Author Contributions: Conceptualization, M.L. and J.M.S.; methodology, M.L., T.H.N. and L.E.R.; formal analysis, M.L. and J.M.S.; resources, P.S.J., C.N. and S.R.L.; data curation, M.L., C.N. and J.M.S.; writing-original draft preparation, M.L. and J.M.S.; writing—review and editing, M.L. and J.M.S.; supervision, J.M.S. and S.R.L.; project administration, J.M.S.; funding acquisition, J.M.S. and S.R.L. All authors have read and agreed to the published version of the manuscript.

Funding: This research and the APC, were funded by The Australian National Health and Medical Research Council (NHMRC), grant numbers APP1162560 and APP1113867. ML was funded by a UQ postgraduate research scholarship.

Institutional Review Board Statement: This study was conducted according to the guidelines of the Declaration of Helsinki and approved human research ethics committees of the National Hospital for Neurology and Neurosurgery, the Royal Brisbane and Women's Hospital and The University of Queensland (approval numbers 2005000785, HREC/2005/022; originally approved 2005).

Informed Consent Statement: Patient consent was waived as this study used archival material in excess of diagnostic requirements, and most of the patients were deceased.

Data Availability Statement: The data presented in this study are available in this article (and Supplementary Materials).

Acknowledgments: We would like to thank all the patients who donate tissue for research purposes, and institutions that indirectly fund biobanking infrastructure. We thank the Royal Brisbane and Women's Hospital Pharmacy for donating aliquots of trastuzumab and pertuzumab for this study. We also acknowledge Peter Bankhead from the Northern Ireland Molecular Pathology Laboratory (Queen's University, Belfast, UK) for expert advice on the development of QuPath and Image J scripts. 
Conflicts of Interest: The authors declare no conflict of interest. The funders had no role in the design of the study; in the collection, analyses, or interpretation of data; in the writing of the manuscript, or in the decision to publish the results.

\section{References}

1. AIWH. Cancer in Australia: An Overview 2014. In Cancer Series No 90; Cat. no. CAN 88; AIHW: Canberra, Australia, 2014.

2. Pestalozzi, B.C.; Zahrieh, D.; Price, K.N.; Holmberg, S.B.; Lindtner, J.; Collins, J.; Crivellari, D.; Fey, M.F.; Murray, E.; Pagani, O.; et al. Identifying breast cancer patients at risk for Central Nervous System (CNS) metastases in trials of the International Breast Cancer Study Group (IBCSG). Ann. Oncol. 2006, 17, 935-944. [CrossRef] [PubMed]

3. Pelletier, E.M.; Shim, B.; Goodman, S.; Amonkar, M.M. Epidemiology and economic burden of brain metastases among patients with primary breast cancer: Results from a US claims data analysis. Breast Cancer Res. Treat. 2007, 108, 297-305. [CrossRef] [PubMed]

4. Wang, R.; Zhu, Y.; Liu, X.; Liao, X.; He, J.; Niu, L. The Clinicopathological features and survival outcomes of patients with different metastatic sites in stage IV breast cancer. BMC Cancer 2019, 19, 1091. [CrossRef]

5. Patel, A.; Unni, N.; Peng, Y. The Changing Paradigm for the Treatment of HER2-Positive Breast Cancer. Cancers 2020, 12,2081 [CrossRef]

6. Palmieri, D.; Bronder, J.L.; Herring, J.M.; Yoneda, T.; Weil, R.J.; Stark, A.M.; Kurek, R.; Vega-Valle, E.; Feigenbaum, L.; Halverson, D.; et al. Her-2 Overexpression Increases the Metastatic Outgrowth of Breast Cancer Cells in the Brain. Cancer Res. 2007, 67, 4190-4198. [CrossRef]

7. Martin, A.M.; Cagney, D.N.; Catalano, P.J.; Warren, L.E.; Bellon, J.R.; Punglia, R.S.; Claus, E.B.; Lee, E.Q.; Wen, P.Y.; Haas-Kogan, D.A.; et al. Brain Metastases in Newly Diagnosed Breast Cancer: A Population-Based Study. JAMA Oncol. 2017, 3, 1069-1077. [CrossRef] [PubMed]

8. Berghoff, A.S.; Schur, S.; Füreder, L.M.; Gatterbauer, B.; Dieckmann, K.; Widhalm, G.; Hainfellner, J.; Zielinski, C.C.; Birner, P.; Bartsch, R.; et al. Descriptive statistical analysis of a real life cohort of 2419 patients with brain metastases of solid cancers. ESMO Open 2016, 1, e000024. [CrossRef] [PubMed]

9. Hsieh, A.C.; Moasser, M.M. Targeting HER proteins in cancer therapy and the role of the non-target HER3. Br. J. Cancer 2007, 97, 453-457. [CrossRef]

10. Hohensee, I.; Lamszus, K.; Riethdorf, S.; Meyer-Staeckling, S.; Glatzel, M.; Matschke, J.; Witzel, I.; Westphal, M.; Brandt, B.; Müller, V.; et al. Frequent Genetic Alterations in EGFR- and HER2-Driven Pathways in Breast Cancer Brain Metastases. Am. J. Pathol. 2013, 183, 83-95. [CrossRef]

11. Saunus, J.M.; Reed, A.E.M.; Lim, M.; Lakhani, S. Breast Cancer Brain Metastases: Clonal Evolution in Clinical Context. Int. J. Mol. Sci. 2017, 18, 152. [CrossRef]

12. Park, Y.H.; Park, M.J.; Ji, S.H.; Yi, S.Y.; Lim, D.H.; Nam, D.H.; Lee, J.-I.; Park, W.; Choi, D.H.; Huh, S.J.; et al. Trastuzumab treatment improves brain metastasis outcomes through control and durable prolongation of systemic extracranial disease in HER2-overexpressing breast cancer patients. Br. J. Cancer 2009, 100, 894-900. [CrossRef] [PubMed]

13. Von Minckwitz, G.; Procter, M.; de Azambuja, E.; Zardavas, D.; Benyunes, M.; Viale, G.; Suter, T.; Arahmani, A.; Rouchet, N.; Clark, E.; et al. Adjuvant Pertuzumab and Trastuzumab in Early HER2-Positive Breast Cancer. N. Engl. J. Med. 2017, 377, 122-131. [CrossRef]

14. Olson, E.M.; Abdel-Rasoul, M.; Maly, J.; Wu, C.S.; Lin, N.U.; Shapiro, C.L. Incidence and risk of central nervous system metastases as site of first recurrence in patients with HER2-positive breast cancer treated with adjuvant trastuzumab. Ann. Oncol. 2013, 24, 1526-1533. [CrossRef]

15. Brufsky, A.M.; Mayer, M.; Rugo, H.S.; Kaufman, P.A.; Tan-Chiu, E.; Tripathy, D.; Tudor, I.C.; Wang, L.I.; Brammer, M.G.; Shing, M.; et al. Central Nervous System Metastases in Patients with HER2-Positive Metastatic Breast Cancer: Incidence, Treatment, and Survival in Patients from registHER. Clin. Cancer Res. 2011, 17, 4834-4843. [CrossRef] [PubMed]

16. Von Minckwitz, G.; Huang, C.S.; Mano, M.S.; Loibl, S.; Mamounas, E.P.; Untch, M.; Wolmark, N.; Rastogi, P.; Schneeweiss, A.; Redondo, A.; et al. Trastuzumab Emtansine for Residual Invasive HER2-Positive Breast Cancer. N. Engl. J. Med. 2019, 380, 617-628. [CrossRef] [PubMed]

17. Swain, S.M.; Baselga, J.; Miles, D.; Im, Y.-H.; Quah, C.; Lee, L.F.; Cortes, J. Incidence of central nervous system metastases in patients with HER2-positive metastatic breast cancer treated with pertuzumab, trastuzumab, and docetaxel: Results from the randomized phase III study CLEOPATRA. Ann. Oncol. 2014, 25, 1116-1121. [CrossRef]

18. Murthy, R.K.; Loi, S.; Okines, A.; Paplomata, E.; Hamilton, E.; Hurvitz, S.A.; Lin, N.U.; Borges, V.; Abramson, V.; Anders, C.; et al. Tucatinib, Trastuzumab, and Capecitabine for HER2-Positive Metastatic Breast Cancer. N. Engl. J. Med. 2020, 382, 597-609. [CrossRef]

19. Stemmler, H.J.; Kahlert, S.; Siekiera, W.; Untch, M.; Heinrich, B.; Heinemann, V. Characteristics of patients with brain metastases receiving trastuzumab for HER2 overexpressing meta-static breast cancer. Breast 2006, 15, 219-225. [CrossRef]

20. Stavrou, E.; Winer, E.; Lin, N. How we treat HER2-positive brain metastases. ESMO Open 2021, 6, 100256. [CrossRef]

21. Taskar, K.S.; Rudraraju, V.; Mittapalli, R.K.; Samala, R.; Thorsheim, H.R.; Lockman, J.; Gril, B.; Hua, E.; Palmieri, D.; Polli, J.; et al. Lapatinib Distribution in HER2 Overexpressing Experimental Brain Metastases of Breast Cancer. Pharm. Res. 2011, $29,770-781$. [CrossRef] 
22. Lockman, P.R.; Mittapalli, R.K.; Taskar, K.S.; Rudraraju, V.; Gril, B.; Bohn, K.A.; Adkins, C.E.; Roberts, A.; Thorsheim, H.R.; Gaasch, J.A.; et al. Heterogeneous blood-tumor barrier permeability determines drug efficacy in experimental brain metas-tases of breast cancer. Clin. Cancer Res. 2010, 16, 5664-5678. [CrossRef]

23. Mortimer, J.E.; Bading, J.R.; Colcher, D.M.; Conti, P.S.; Frankel, P.H.; Carroll, M.I.; Tong, S.; Poku, E.; Miles, J.K.; Shively, J.E.; et al. Functional imaging of HER2-positive metastatic breast cancer using (64)Cu-DOTA-trastuzumab PET. J. Nucl. Med. 2014, 55, 23-29. [CrossRef] [PubMed]

24. Dijkers, E.C.; Oude Munnink, T.H.; Kosterink, J.G.; Brouwers, A.H.; Jager, P.L.; De Jong, J.R.; Van Dongen, G.A.; Schroder, C.P.; Lub-de Hooge, M.N.; de Vries, E.G. Biodistribution of 89Zr-trastuzumab and PET Imaging of HER2-Positive Lesions in Patients With Metastatic Breast Cancer. Clin. Pharmacol. Ther. 2010, 87, 586-592. [CrossRef] [PubMed]

25. Tamura, K.; Kurihara, H.; Yonemori, K.; Tsuda, H.; Suzuki, J.; Kono, Y.; Honda, N.; Kodaira, M.; Yamamoto, H.; Yunokawa, M.; et al. 64Cu-DOTA-Trastuzumab PET Imaging in Patients with HER2-Positive Breast Cancer. J. Nucl. Med. 2013, 54, 1869-1875. [CrossRef]

26. Kodack, D.P.; Askoxylakis, V.; Ferraro, G.B.; Fukumura, D.; Jain, R.K. Emerging Strategies for Treating Brain Metastases from Breast Cancer. Cancer Cell 2015, 27, 163-175. [CrossRef]

27. Kodack, D.P.; Askoxylakis, V.; Ferraro, G.B.; Sheng, Q.; Badeaux, M.; Goel, S.; Qi, X.; Shankaraiah, R.; Cao, Z.A.; Ramjiawan, R.R.; et al. The brain microenvironment mediates resistance in luminal breast cancer to PI3K inhibition through HER3 activation. Sci. Transl. Med. 2017, 9, eaal4682. [CrossRef]

28. Lampson, L.A. Monoclonal antibodies in neuro-oncology: Getting past the blood-brain barrier. MAbs 2011, 3, 153-160. [CrossRef]

29. Sun, M.; Behrens, C.; Feng, L.; Ozburn, N.; Tang, X.; Yin, G.; Komaki, R.; Varella-Garcia, M.; Hong, W.K.; Aldape, K.D.; et al. HER Family Receptor Abnormalities in Lung Cancer Brain Metastases and Corresponding Primary Tumors. Clin. Cancer Res. 2009, 15, 4829-4837. [CrossRef]

30. Saunus, J.M.; Quinn, M.C.; Patch, A.-M.; Pearson, J.V.; Bailey, P.J.; Nones, K.; Reed, A.E.M.; Miller, D.; Wilson, P.J.; Al-Ejeh, F.; et al. Integrated genomic and transcriptomic analysis of human brain metastases identifies alterations of potential clinical significance. J. Pathol. 2015, 237, 363-378. [CrossRef] [PubMed]

31. Kalita-de Croft, P.; Lim, M.; Chittoory, H.; De Luca, X.M.; Kutasovic, J.R.; Day, B.W.; Al-Ejeh, F.; Simpson, P.T.; Reed, A.M.; Lakhani, S.R.; et al. Clinicopathologic significance of nuclear HER4 and phospho-YAP(S127) in human breast cancers and matching brain metastases. Ther. Adv. Med. Oncol. 2020, 12, 1758835920946259. [CrossRef]

32. Da Silva, L.; Simpson, P.T.; Smart, C.E.; Cocciardi, S.; Waddell, N.; Lane, A.; Morrison, B.J.; Vargas, A.C.; Healey, S.; Beesley, J.; et al HER3 and downstream pathways are involved in colonization of brain metastases from breast cancer. Breast Cancer Res. 2010, 12, R46. [CrossRef] [PubMed]

33. Sliwkowski, M.X.; Schaefer, G.; Akita, R.W.; Lofgren, J.A.; Fitzpatrick, V.D.; Nuijens, A.; Fendly, B.M.; Cerione, R.A.; Vandlen, R.L.; Carraway, K.L. Coexpression of erbB2 and erbB3 proteins reconstitutes a high affinity receptor for heregulin. J. Biol. Chem. 1994, 269, 14661-14665. [CrossRef]

34. Soltoff, S.P.; Carraway, K.L., 3rd; Prigent, S.A.; Gullick, W.G.; Cantley, L.C. ErbB3 is involved in activation of phosphatidylinositol 3-kinase by epidermal growth factor. Mol. Cell. Biol. 1994, 14, 3550-3558. [PubMed]

35. Baselga, J.; Swain, S.M. Novel anticancer targets: Revisiting ERBB2 and discovering ERBB3. Nat. Cancer 2009, 9, 463-475. [CrossRef]

36. Clark, A.S.; West, K.; Streicher, S.; A Dennis, P. Constitutive and inducible Akt activity promotes resistance to chemotherapy, trastuzumab, or tamoxifen in breast cancer cells. Mol. Cancer Ther. 2002, 1, 707-717.

37. Xia, W.; Petricoin, E.F.; Zhao, S.; Liu, L.; Osada, T.; Cheng, Q.; Wulfkuhle, J.D.; Gwin, W.R.; Yang, X.; Gallagher, R.I.; et al. An heregulin-EGFR-HER3 autocrine signaling axis can mediate acquired lapatinib resistance in HER2+ breast cancer models. Breast Cancer Res. 2013, 15, R85. [CrossRef]

38. Wang, D.D.; Ma, L.; Wong, M.P.; Lee, V.H.F.; Yan, H. Contribution of EGFR and ErbB-3 Heterodimerization to the EGFR MutationInduced Gefitinib- and Erlo-tinib-Resistance in Non-Small-Cell Lung Carcinoma Treatments. PLoS ONE 2015, 10, e0128360.

39. Ma, J.; Lyu, H.; Huang, J.; Liu, B. Targeting of erbB3 receptor to overcome resistance in cancer treatment. Mol. Cancer 2014, 13, 105. [CrossRef]

40. Yao, E.; Zhou, W.; Lee-Hoeflich, S.T.; Truong, T.; Haverty, P.M.; Eastham-Anderson, J.; Lewin-Koh, N.; Gunter, B.; Belvin, M.; Murray, L.J.; et al. Suppression of HER2/HER3-mediated growth of breast cancer cells with combinations of GDC-0941 PI3K in-hibitor, trastuzumab, and pertuzumab. Clin. Cancer Res. 2009, 15, 4147-4156. [CrossRef]

41. Koutras, A.K.; Fountzilas, G.; Kalogeras, K.T.; Starakis, I.; Iconomou, G.; Kalofonos, H.P. The upgraded role of HER3 and HER4 receptors in breast cancer. Crit. Rev. Oncol. 2010, 74, 73-78. [CrossRef] [PubMed]

42. Sergina, N.V.; Rausch, M.; Wang, D.; Blair, J.; Hann, B.; Shokat, K.M.; Moasser, M.M. Escape from HER-family tyrosine kinase inhibitor therapy by the kinase-inactive HER3. Nature 2007, 445, 437-441. [CrossRef] [PubMed]

43. Narayan, M.; Wilken, J.A.; Harris, L.N.; Baron, A.; Kimbler, K.D.; Maihle, N.J. Trastuzumab-Induced HER Reprogramming in "Resistant" Breast Carcinoma Cells. Cancer Res. 2009, 69, 2191-2194. [CrossRef]

44. Liu, B.; Ordonez-Ercan, D.; Fan, Z.; Edgerton, S.M.; Yang, X.; Thor, A.D. Downregulation of erbB3 abrogates erbB2-mediated tamoxifen resistance in breast cancer cells. Int. J. Cancer 2007, 120, 1874-1882. [CrossRef] [PubMed]

45. Haikala, H.M.; Jänne, P.A. Thirty Years of HER3: From Basic Biology to Therapeutic Interventions. Clin. Cancer Res. 2021, 27, 3528-3539. [CrossRef] [PubMed] 
46. Barretina, J.; Caponigro, G.; Stransky, N.; Venkatesan, K.; Margolin, A.A.; Kim, S.; Wilson, C.J.; Lehár, J.; Kryukov, G.V.; Sonkin, D.; et al. Addendum: The Cancer Cell Line Encyclopedia enables predictive modelling of anticancer drug sensitivity. Nature 2018, 565, E5-E6. [CrossRef]

47. The Cancer Cell Line Encyclopedia Consortium; The Genomics of Drug Sensitivity in Cancer Consortium. Pharmacogenomic agreement between two cancer cell line data sets. Nature 2015, 528, 84-87. [CrossRef]

48. Rondón-Lagos, M.; Di Cantogno, L.V.; Rangel, N.; Mele, T.; Ramírez-Clavijo, S.R.; Scagliotti, G.; Marchio, C.; Sapino, A. Unraveling the chromosome 17 patterns of FISH in interphase nuclei: An in-depth analysis of the HER2 amplicon and chromosome 17 centromere by karyotyping, FISH and M-FISH in breast cancer cells. BMC Cancer 2014, 14, 922. [CrossRef]

49. Saunus, J.M.; Smart, C.E.; Kutasovic, J.R.; Johnston, R.; Croft, P.K.-D.; Miranda, M.; Rozali, E.N.; Vargas, A.C.; Reid, L.E.; Lorsy, E.; et al. Multidimensional phenotyping of breast cancer cell lines to guide preclinical research. Breast Cancer Res. Treat. 2017, 167, 289-301. [CrossRef] [PubMed]

50. Söderberg, O.; Gullberg, M.; Jarvius, M.; Ridderstråle, K.; Leuchowius, K.-J.; Jarvius, J.; Wester, K.; Hydbring, P.; Bahram, F.; Larsson, L.-G.; et al. Direct observation of individual endogenous protein complexes in situ by proximity ligation. Nat. Methods 2006, 3, 995-1000. [CrossRef] [PubMed]

51. Bankhead, P.; Loughrey, M.B.; Fernández, J.A.; Dombrowski, Y.; McArt, D.G.; Dunne, P.D.; McQuaid, S.; Gray, R.T.; Murray, L.J.; Coleman, H.G.; et al. QuPath: Open source software for digital pathology image analysis. Sci. Rep. 2017, 7, 16878. [CrossRef] [PubMed]

52. Wikman, H.; Lamszus, K.; Detels, N.; Uslar, L.; Wrage, M.; Benner, C.; Hohensee, I.; Ylstra, B.; Eylmann, K.; Zapatka, M.; et al. Relevance of PTEN loss in brain metastasis formation in breast cancer patients. Breast Cancer Res. 2012, 14, R49. [CrossRef]

53. Zhang, L.; Zhang, S.; Yao, J.; Lowery, F.J.; Zhang, Q.; Huang, W.-C.; Li, P.; Li, M.; Wang, X.; Zhang, C.; et al. Microenvironmentinduced PTEN loss by exosomal microRNA primes brain metastasis outgrowth. Nature 2015, 527, 100-104. [CrossRef] [PubMed]

54. Chakrabarty, A.; Rexer, B.N.; Wang, S.E.; Cook, R.S.; Engelman, J.A.; Arteaga, C.L.; Carlos, L.A. H1047R phosphatidylinositol 3-kinase mutant enhances HER2-mediated transformation by heregulin production and activation of HER3. Oncogene 2010, 29, 5193-5203. [CrossRef] [PubMed]

55. Leontiadou, H.; Galdadas, I.; Athanasiou, C.; Cournia, Z. Insights into the mechanism of the PIK3CA E545K activating mutation using MD simulations. Sci. Rep. 2018, 8, 15544. [CrossRef] [PubMed]

56. Blair, B.G.; Wu, X.; Zahari, M.S.; Mohseni, M.; Cidado, J.; Wong, H.Y.; Beaver, J.A.; Cochran, R.L.; Zabransky, D.J.; Croessmann, S.; et al. A phosphoproteomic screen demonstrates differential dependence on HER3 for MAP kinase pathway acti-vation by distinct PIK3CA mutations. Proteomics 2015, 15, 318-326. [CrossRef]

57. Uhlén, M.; Fagerberg, L.; Hallström, B.M.; Lindskog, C.; Oksvold, P.; Mardinoglu, A.; Sivertsson, Å.; Kampf, C.; Sjöstedt, E.; Asplund, A.; et al. Tissue-Based Map of the Human Proteome. Science 2015, 347, 1260419. [CrossRef] [PubMed]

58. Savinainen, K.J.; Saramäki, O.R.; Linja, M.J.; Bratt, O.; Tammela, T.L.; Isola, J.J.; Visakorpi, T. Expression and Gene Copy Number Analysis of ERBB2 Oncogene in Prostate Cancer. Am. J. Pathol. 2002, 160, 339-345. [CrossRef]

59. Calvo, B.F.; Levine, A.M.; Marcos, M.; Collins, Q.F.; Iacocca, M.V.; Caskey, L.S.; Gregory, C.W.; Lin, Y.; Whang, Y.E.; Earp, H.S.; et al. Human epidermal receptor-2 expression in prostate cancer. Clin. Cancer Res. 2003, 9, 1087.

60. Guven, D.C.; Kaya, M.B.; Fedai, B.; Ozden, M.; Yildirim, H.C.; Kosemehmetoglu, K.; Kertmen, N.; Dizdar, O.; Uner, A.; Aksoy, S. HER2-low breast cancer could be associated with an increased risk of brain metastasis. Int. J. Clin. Oncol. 2021, 1-8. [CrossRef]

61. Schwarz, L.; E Hutchinson, K.E.; Rexer, B.N.; Estrada, M.V.; Ericsson, P.G.; E Sanders, M.E.; Dugger, T.C.; Formisano, L.; GuerreroZotano, A.; Red-Brewer, M.; et al. An ERBB1-3 Neutralizing Antibody Mixture with High Activity against Drug-Resistant HER2+ Breast Cancers with ERBB Ligand Overexpression. J. Natl. Cancer Inst. 2017, 109. [CrossRef]

62. Jhaveri, K.; Drago, J.Z.; Shah, P.D.; Wang, R.; Pareja, F.; Ratzon, F.; Iasonos, A.; Patil, S.; Rosen, N.; Fornier, M.N.; et al. A Phase I Study of Alpelisib in Combination with Trastuzumab and LJM716 in Patients with PIK3CA-Mutated HER2-Positive Metastatic Breast Cancer. Clin. Cancer Res. 2021, 27, 3867-3875. [CrossRef] [PubMed]

63. Reynolds, K.L.; Bedard, P.L.; Lee, S.-H.; Lin, C.-C.; Tabernero, J.; Alsina, M.; Cohen, E.; Baselga, J.; Blumenschein, G., Jr.; Graham, D.M.; et al. A phase I open-label dose-escalation study of the anti-HER3 monoclonal antibody LJM716 in patients with advanced squamous cell carcinoma of the esophagus or head and neck and HER2-overexpressing breast or gastric cancer. BMC Cancer 2017, 17, 1-11. [CrossRef]

64. Lua, W.H.; Ling, W.L.; Yeo, J.Y.; Poh, J.J.; Lane, D.P.; Gan, S.K. The effects of Antibody Engineering CH and CL in Trastuzumab and Pertuzumab recombinant models: Impact on antibody production and antigen-binding. Sci. Rep. 2018, 8, 718. [CrossRef] [PubMed]

65. Brastianos, P.K.; Carter, S.L.; Santagata, S.; Cahill, D.; Taylor-Weiner, A.; Jones, R.T.; Van Allen, E.M.; Lawrence, M.S.; Horowitz, P.; Cibulskis, K.; et al. Genomic Characterization of Brain Metastases Reveals Branched Evolution and Potential Therapeutic Targets. Cancer Discov. 2015, 5, 1164-1177. [CrossRef]

66. Steinkamp, M.P.; Low-Nam, S.T.; Yang, S.; Lidke, K.A.; Lidke, D.S.; Wilson, B.S. erbB3 is an Active Tyrosine Kinase Capable of Homo- and Heterointeractions. Mol. Cell. Biol. 2014, 34, 965-977. [CrossRef] [PubMed]

67. Jeong, J.; Kim, W.; Kim, L.K.; VanHouten, J.; Wysolmerski, J.J. HER2 signaling regulates HER2 localization and membrane retention. PLoS ONE 2017, 12, e0174849. [CrossRef] [PubMed] 